\title{
Innovated Safety Inspection System on Construction Site Based on Mobile Phone Application
}

\author{
Tao Wang ${ }^{1, \mathrm{a}}$, Dongping Fang ${ }^{2, \mathrm{~b}}$ and Guijun $\mathrm{Li}^{3, \mathrm{c}}$ \\ ${ }^{1}$ School of Management Science and Engineering, Central University of \\ Finance and Economics, Beijing, 100081, China \\ ${ }^{2}$ Dept. of Construction Management, Tsinghua University, Beijing \\ 100084, China \\ ${ }^{3}$ School of Management Science and Engineering, Central University of \\ Finance and Economics, Beijing, 100081, China \\ a wangtaothu@163.com, bangdp@tsinghua.edu.cn, ${ }^{c}$ gcjj2002@163.com
}

\begin{abstract}
.
Safety inspection on construction site is an important method to prevent hazards around the site and unsafe behaviors of the workers. The traditional safety inspection system has several drawbacks. This paper developed an innovated safety inspection system on construction site based on mobile phone application. The new safety inspection system can greatly reduce the demand of experienced safety inspectors on construction site and integrate the safety inspection work of multi-projects at the company level, which increase the value of labor power of experienced safety manager. The composite incremental cost of the safety inspection system can be negative, considering both the instrument and human cost. Meanwhile, the new safety inspection system can reserve the detail of safety inspection for the safety management department of construction companies to make targeted management decisions.
\end{abstract}

Keywords: List the keywords covered in your paper. These keywords will also be used by the publisher to produce a keyword index.

\section{Introduction}

Construction rates one of the highest occupational accidents among the industries all over the world, leading to workers' fatalities, injuries and other 
losses [1, 2]. Safety inspection on construction site is a traditional and widely-used method to prevent hazards around the site and unsafe behaviors of the workers [3-5]. However, there are several drawbacks of the traditional inspection system [6]. For Example, there are not adequate competent safety inspectors on site, especially in developing countries with large amount of construction in progress. The safety inspectors on site are usually in charge of too large construction areas. They need to undertake burdensome duties and bear crucial responsibilities. But their relatively low earning usually do not match the work content. Besides, the process and content of safety inspection on site are not easy to be standardized on every site [6]. It depends more on the experience of the safety inspectors. This feature aggravates the shortage of safety inspectors with rich experience. The coarse management system can not keep the details of the safety statement and form data records. The small hazard source and near-miss incidents can not be recorded and analyzed as the evidence for improving safety management.

In recent years, some researchers are trying to apply computer technology, intelligent technology and web-based technology to enhancing the efficiency and effectiveness of safety management. Building Information Models (BIM) such as 3D or 4D technology can be applied to visualize the site situation in design stage or on real time. Potentially unsafe activities and conditions can be detected and avoided before construction begins [7-9] or at the ongoing project [10]. Sensor technology and remote data transmission technology can be applied to monitoring both hazardous situation of infrastructure construction $[11,12]$ and unsafe human behaviors $[8,10,13,14]$. Local network and internet technology can be applied to collect the real-time data of safety situation on site and then transmit the data of multiple construction projects into a centralized database, where safety assessment can be implemented $[15,16]$. Managers can use such real-time information for making safety management decisions at construction sites [15].

Although the application of new technology can improve the practices of safety management. However, since construction is a comparatively low profit rate industry, it is always not easy to popularize the application of sensors, 
computers and other expensive instruments on construction site. Some application of new technology even increase the specialized operation workers on site, which may lead to greatly increase of cost. It is a big barrier for the technology promotion in construction industry, especially in developing countries. Lin et al [6] developed an innovated iPad application which can help safety inspectors carrying out the inspection work on construction site. It also allows consistent data collection for advanced safety and health data analysis. However, the method still need a lot of experienced inspectors and extra instrument.

This paper developed an innovated safety inspection system on construction site based on mobile phone application. The new safety inspection system can greatly reduce the demand of experienced safety inspectors on construction site and integrate the safety inspection work of multi-projects at the company level, which increase the value of labor power of experienced safety manager. Since smart phone and mobile wireless data transmission has been widely used at low price even in developing countries, such as China, the composite incremental cost of the safety inspection system can be negative, considering both the instrument and human cost. Meanwhile, the new safety inspection system can reserve the detail of safety inspection for the safety management department of construction companies to make targeted management decisions.

\section{Methodology}

Framework of the safety inspection system. Fig. 1 presented the framework of the safety inspection system. The main idea of the framework is to simplify the inspection work on site and reduce the uncertainty during the process of inspection. The main inspection work and decision can be implemented at the company level. The steps of the safety inspection are as follows: 


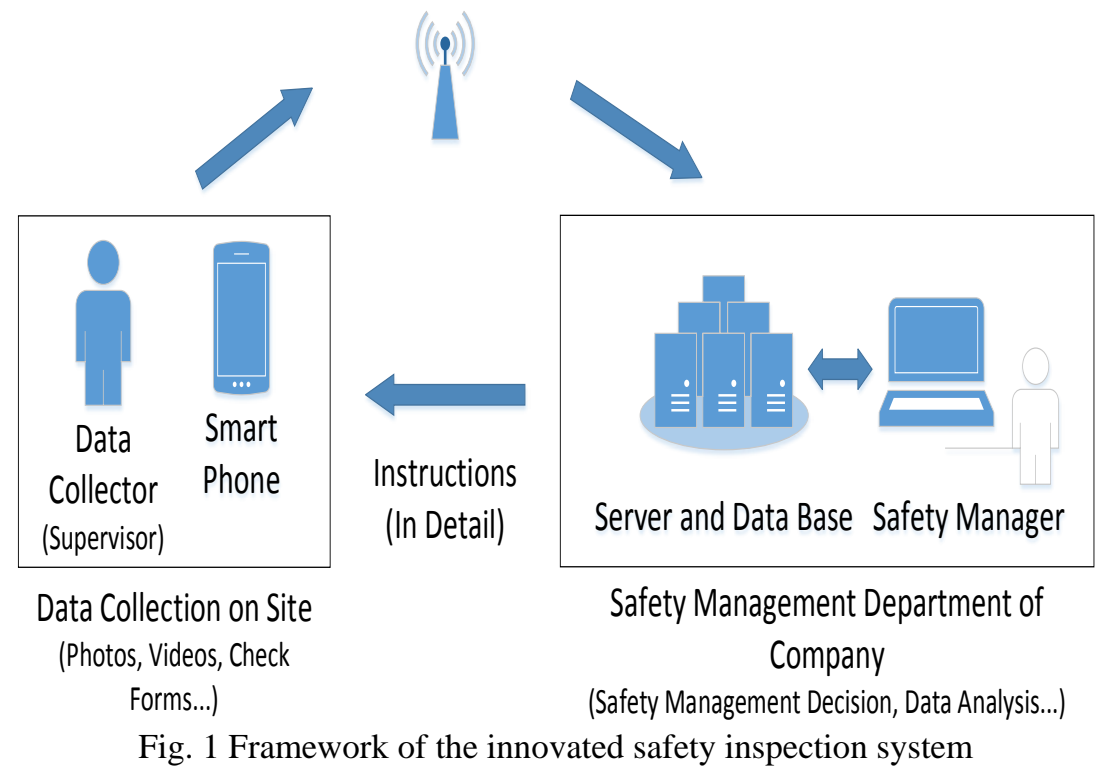

Data collection on site. Data collector use the safety check list application on smart phones to collect safety inspection data. The form of data in the safety check list can be photos, videos, check forms, etc., according to the feature of the required information. The data collectors only need the basic safety knowledge, since they only collect data following the instruction of the safety check list. As a matter of fact, the supervisor can easily do the job while he/she walk through the construction site, which means the experienced safety inspectors/managers do not have to be at site every day.

Data transmission. The collected data will be transmit to the server and data base in the construction company directly by the mobile network. Nowadays, the data package service of telecommunications corporations are quite cheap and the data transmission speed is also fast enough.

Data process and decision making. Specialized safety managers with rich safety management experience make decisions based on the information from the collected data. Each safety manager can be in charge of several construction projects. It should be noticed that the safety managers should also do inspection on site from time to time and at the critical work node to get familiar with the special 
environment or each project, which may help them make proper decisions and instructions.

Feedback to construction site. Safety manager will provide instructions to the project managers or supervisors on construction site by mobile phone based on their decisions. The safety check list can be also adjusted according to the inspection results.

\section{Discussion}

Comparison to the traditional safety inspection system. Fig. 2 presented the framework of traditional safety inspection system. Safety inspectors implement the inspection process using check forms or just give oral instruction to the workers. The reports submitted to the safety manager usually miss a lot of valuable information. The safety managers in the company do not know the real safety situation of the projects. The instructions from the company to the construction site are inevitable to be rough outlines. The safety management level of the company can not be improved under this framework. On the contrary, the new safety inspection system has several advantages:

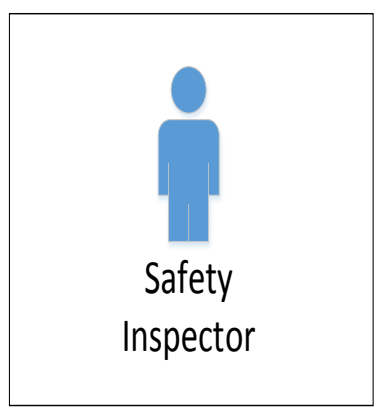

Safety Inspection on Site

(Check Forms or just Oral

Instruction)

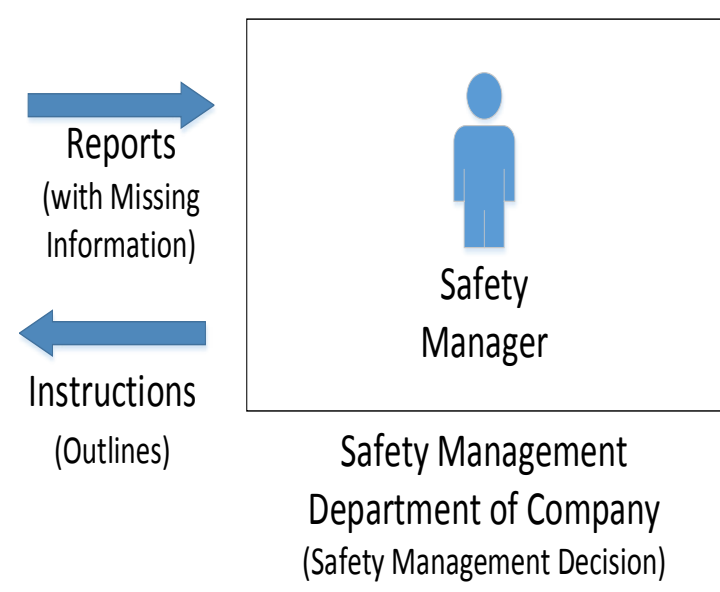

(Safety Management Decision)

Fig. 2 Framework of traditional safety inspection system 
More precise decision and instruction. Data process and safety inspection work implemented by the experienced safety manager guarantees the quality of safety inspection.

Less human resource requirements. The data collector on construction site only need basic training. The scarce safety managers with rich experience can produce the best form of their career. The construction company can save a lot of cost on human resource.

Small incremental cost on instrument. Nowadays, more and more people owns more than one smart phones. The price of data package service is acceptable. The data transmission and process program can be easily realized on the company server. The incremental is reasonable enough.

Storable data in more detail. The data of safety inspection can be in more detail, such as small hazard source and near-miss incidents, which are the more valuable information for improving the safety management level of the company. The data can also be stored for timeline and inter-project analysis.

Possibility for improving the management level. The content and the form of the safety check list application can be both updated according to the safety inspection results. The safety check list can also be adjusted according to the features of different projects. Delicacy safety management can push the improvement of the company's safety management level.

\section{Conclusion}

This paper developed an innovated safety inspection system on construction site based on mobile phone application. The new safety inspection system can greatly reduce the demand of experienced safety inspectors on construction site and integrate the safety inspection work of multi-projects at the company level. The new safety inspection system can reserve the detail of safety inspection for the safety management department of construction companies to make targeted management decisions. The critical point of the safety inspection system is the 
form of safety check list and the key point inspection method. Future studies will focus on the formation and validation of the checklist.

\section{Acknowledgements}

Acknowledgments are addressed to the National Natural Science Foundation of China (Grant No. 71401191) and 121 Youth PhD Development Foundation of Central University of Finance and Economics (Grant No. QBJ1411).

\section{References}

[1] Fang, D., Y. Chen, and L. Wong, Safety Climate in Construction Industry: A Case Study in Hong Kong. Journal of Construction Engineering and Management, 2006. 132(6): p. 573-584.

[2] Fang, D. and H. Wu, Development of a Safety Culture Interaction (SCI) model for construction projects. Safety Science, 2013. 57(0): p. 138-149.

[3] Abudayyeh, O., et al., An investigation of management's commitment to construction safety. International Journal of Project Management, 2006. 24(2): p. 167-174.

[4] Aksorn, T. and B.H.W. Hadikusumo, Critical success factors influencing safety program performance in Thai construction projects. Safety Science, 2008. 46(4): p. 709-727.

[5] Ling, F.Y.Y., M. Liu, and Y.C. Woo, Construction fatalities in Singapore. International Journal of Project Management, 2009. 27(7): p. 717-726.

[6] Lin, K.-Y., et al., A user-centered information and communication technology (ICT) tool to improve safety inspections. Automation in Construction, 2014. 48(0): p. 53-63.

[7] Hu, Z. and J. Zhang, BIM- and 4D-based integrated solution of analysis and management for conflicts and structural safety problems during construction: 2. Development and site trials. Automation in Construction, 2011. 20(2): p. 167-180. 
[8] Zhang, S., et al., Building Information Modeling (BIM) and Safety: Automatic Safety Checking of Construction Models and Schedules. Automation in Construction, 2013. 29(0): p. 183-195.

[9] Zhou, Y., L.Y. Ding, and L.J. Chen, Application of 4D visualization technology for safety management in metro construction. Automation in Construction, 2013. 34(0): p. 25-36.

[10] Cheng, T. and J. Teizer, Real-time resource location data collection and visualization technology for construction safety and activity monitoring applications. Automation in Construction, 2013. 34(0): p. 3-15.

[11] Ma, L., H.B. Luo, and H.R. Chen, Safety risk analysis based on a geotechnical instrumentation data warehouse in metro tunnel project. Automation in Construction, 2013. 34(0): p. 75-84.

[12] Wang, J., S. Zhang, and J. Teizer, Geotechnical and safety protective equipment planning using range point cloud data and rule checking in building information modeling. Automation in Construction, (0).

[13] Riaz, Z., et al., CoSMoS: A BIM and wireless sensor based integrated solution for worker safety in confined spaces. Automation in Construction, 2014. 45(0): p. 96-106.

[14] Teizer, J., et al., Autonomous pro-active real-time construction worker and equipment operator proximity safety alert system. Automation in Construction, 2010. 19(5): p. 630-640.

[15] Aguilar, G.E. and K.N. Hewage, IT based system for construction safety management and monitoring: C-RTICS2. Automation in Construction, 2013. 35(0): p. 217-228.

[16] Ding, L.Y. and C. Zhou, Development of web-based system for safety risk early warning in urban metro construction. Automation in Construction, 2013. 34(0): p. 45-55. 